\title{
La vigencia de la Instrucción Dignitas Connubii a la luz del M. P. Mitis ludex
}

\section{The Validity of the Instruction Dignitas Connubii in the Light of M. P. Mitis ludex}

\section{Carlos M. Morán Bustos}

Decano

Tribunal de la Rota de la Nunciatura Apostólica de España. Madrid

cmoran.tribunalrota@gmail.com

Resumen: El presente artículo analiza la Dignitas Connubii a la luz del M. P. Mitis ludex, afirmando el valor y vigencia de aquélla como «instrumento» procesal que permite complementar y desarrollar las diversas instituciones que configuran el proceso de nulidad del matrimonio. El punto de partida es la consideración del Mitis ludex desde la lógica de la continuidad procesal, de hecho han permanecido inalterados los fundamentos esenciales del proceso de nulidad. Esta lógica de la «continuidad procesal legislativa» y de la «continuidad sustantivo-material forense» es la que nos impulsa a echar mano de la Dignitas Connubii con carácter supletorio y de desarrollo de la disciplina codicial a la que -con el presupuesto del art. 6 de la Ratio Procedendi- reenvía el can. 1691 § 3. Más aún: por encima de la vigencia normativa, la Dignitas Connubii seguirá teniendo un valor hermenéutico indubitable.

Palabras clave: Dignitas Connubii, Mitis ludex, Continuidad procesal, Validez de la norma.
Abstract: This article analyses Dignitas Connubii in light of M. P. Mitis ludex, confirming its value and validity as a procedural «instrument» that enables the complementarity and development of the various institutions that comprise the marriage annulment process. The starting point is the consideration of the Mitis ludex from the perspective of procedural continuity; in fact, the essential fundamentals of the annulment process have remained unaltered. It is this logic of «legislative procedural continuity» and of «forensic substantive-material continuity s that prompts reference to Dignitas Connubii as an extension to the discipline set out in Codex 1983, to which (based on the assumption of Art. 6 of the Ratio Procedendi) Canon 1691 \$ 3 refers. Furthermore, beyond the current regulations, the hermeneutic value of Dignitas Connubii remains unquestionable.

Keywords: Dignitas Connubii, Mitis ludex, Procedural Continuity, Validity of the Law. 


\section{INTRODUCCIÓN}

124 de septiembre de 2014, unos días antes del inicio de la Asamblea Ex-
traordinaria del Sínodo de la Familia, el Papa Francisco creaba una Co-
misión encargada de «preparar, según afirmaba el comunicado de la Santa Sede, una propuesta de reforma de los procesos matrimoniales, intentando simplificar el procedimiento, haciéndolo más sencillo y salvaguardando el principio de indisolubilidad del matrimonio». El 8 de septiembre de 2015, unos días antes de que se iniciara la XIV Asamblea General Ordinaria del Sínodo de $2015^{1}$, veía la luz el resultado del trabajo de esta Comisión con la promulgación del M. P. Mitis Iudex Dominus Iesus y el M. P. Mitis et misericors Iesus respectivamente para la Iglesia latina y la oriental, con los que venía a reformar en su totalidad el proceso de nulidad del matrimonio ${ }^{2}$. Apenas habían pa-

${ }^{1}$ Para dicha XIV Asamblea General Ordinaria del Sinodo de 2015 se había preparado un Instrumentum Laboris, y en el mismo se hacía referencia en varios artículos a los procesos de nulidad; en concreto, se hacía referencia a esta cuestión en el n. 115: «se observa un amplio consenso sobre la oportunidad de hacer más accesibles y ágiles, posiblemente gratuitos, los procedimientos para el reconocimiento de los casos de nulidad matrimonial. En cuanto a la gratuidad, algunos sugieren instituir en las diócesis un servicio estable de asesoramiento gratuito. Respecto a la doble sentencia conforme, existe amplia convergencia en orden a abandonarla, salvando la posibilidad de recurso de parte del defensor del vínculo o de una de las partes. Viceversa, no cosecha un consenso unánime la posibilidad de un procedimiento administrativo bajo la responsabilidad del obispo diocesano, ya que algunos ven aspectos problemáticos. En cambio, hay mayor acuerdo sobre la posibilidad de un proceso canónico sumario en los casos de nulidad patente...»; también en el n. 117 del Instrumentum laboris también se decía: «se propone que en cada diócesis se garanticen, de manera gratuita, los servicios de información, asesoramiento y mediación relacionados con la pastoral familiar, especialmente a disposición de personas separadas o de parejas en crisis. Un servicio así cualificado ayudaría a las personas a emprender el recorrido judicial, que en la historia de la Iglesia resulta ser el camino de discernimiento más acreditado para verificar la validez real del matrimonio. Además, de diversas partes, se pide un incremento y una mayor descentralización de los tribunales eclesiásticos, dotándoles de personal cualificado y competente».

2 Algún autor ha hablado de una «refundación» del proceso de nulidad, de un «giro copernicano», llegando a esta conclusión a partir de la constatación de haberse roto la tradicional «centralización normativa procesal» a favor de los obispos diocesanos, ello como aplicación a las causas de nulidad de la genérica descentralización programática del pontificado del Papa Francisco: expresión de ello sería, por ejemplo, la posibilidad de confiar la causa a un juez único «bajo la responsabilidad del obispo», lo que supone la dispensa por parte del obispo del can. $1673 \$ 3$; en esta misma línea estaría la posibilidad de erigir un tribunal interdiocesano de primera instancia por parte del obispo, ello sin la necesidad de «la aprobación de la Sede Apostólica», ello de acuerdo con la mens legislatoris expresado el 8-XI-2015 (n. 2), que vendría a modificar el can. 1423; también estaría en esta misma línea la posibilidad de encomendar las causas a un «tribunal vecino» (can. $1673 \$ 2 b$ ), ello también sin interveción de la Sede Apostólica (corrigiendo el criterio del art. $24 \$ 1$ DC y la PB 124, $3^{\circ}$ ) [cfr. J. LlobeLL, El ejercicio personal de la potestad judicial del obispo diocesano. Algunas consideraciones preliminares al M. P. «Mitis Iudex» y al M. P. «Mitis et Misericors», Revista General de Derecho Canónico y Eclesiástico del Estado 41 (2016) 11-15, en www.iustel.com]. 
sado diez años y medio de la anterior normativa reguladora de la dinámica de los procesos de nulidad del vínculo conyugal, la Instrucción Dignitas Connubii, que entraba en vigor el 25 de enero de 2005.

Desde el punto de vista de la sistemática normativa, en este año que va desde la entrada en vigor de la nueva legislación (8-XII-2015), se han suscitado algunas cuestiones relativas a la vigencia de determinadas legislaciones especiales y/o particulares anteriores. Así, a propósito del alcance del art. $8 \$ \$ 1$ y 2 de la Ratio Procedendi, en el ámbito italiano surgió un debate en que se plantearon temas como el derecho del obispo diocesano de abandonar libremente el tribunal regional para constituir su propio tribunal sin autorización de la Signatura Apostólica, la cuestión de la vigencia o no del M. P. Qua cura ${ }^{3}$, e incluso la propia subsistencia de los tribunales regionales creados, no al amparo del can. 1423, sino bajo la citada norma de Pío XII ${ }^{4}$; en cierto modo, el n. I

${ }^{3}$ Cfr. PÍO XI, Motu proprio «Qua cura» de ordinandis tribunalibus ecclesiasticis Italiae pro causis nullitatis matrimonii decidendis, 8 dicembre 1938, AAS 30 (1938) 410-413. El M. P. Qua cura de Pío XII suponía una verdadera derogación para dicho país del sistema de tribunales de primera y segunda instancia prevista en el CIC 17; entre 1940 y 1968 la Sagrada Congregación para Disciplina de los Sacramentos extendió este sistema a otros países (Filipinas, Canadá, Argentina, Brasil, Francia, Argelia, Colombia, Chile), pasando dicha competencia con la Regimini Ecclesiae Universae de Pablo VI a la Sección Primera de la Signatura Apostólica, que a partir de las Normas de 28-XII-1970, en línea con la doctrina del Concilio Vaticano II sobre la potestad de los obispo, priorizó la voluntad de los obispos de constituir este tipo de tribunales.

4 Muy sucintamente, los momentos principales de este debate son los siguientes: $1^{\circ}$ entrevista del Decano de la Rota romana en L'Osservatore Romano el 8-X-2015, en la que indicaba lo siguiente a propósito del futuro de los tribunales regionales italianos: «Questa legge riforma e riordina in pieno, ex integro, il processo matrimoniale, dando al vescovo il diritto di costituire il suo tribunale diocesano. Cade dunque la legge che prevede i tribunali regionali, esistenti del resto soltanto in alcuni Paesi. All'interno delle singole province ecclesiastiche i vescovi avranno invece facoltà di istituire, se lo riterranno utile, un tribunale interdiocesano con appello al tribunale del metropolita, fatta salva la possibilità di creare, a norma del diritto, tribunali interdiocesani di più province» (P. V. PINTO, Speranza e non paure. Intervista al decano della Rota romana sul nuovo processo matrimoniale, L'Osservatore Romano 155 [2015], 8 ottobre 2015, p. 7); de acuerdo con este parecer de Mons. Pinto, por vía de la revocación total del M. P. Qua cura, los tribunales regionales italianos quedaban suprimidos, de modo que a los obispos diocesanos podían, o crear el propio tribunal diocesano, o acceder a un cercano, o erigir un nuevo tribunal interdiocesano; $2^{\circ}$ Respuesta del Pontificio Consejo para la Interpretación de los Textos Legislativos, no auténtica pero sí publicada en la web de dicho dicho organismo: «gli Ecc.mi Vescovi che eventualmente ritenessero di dover recedere dai Tribunali regionali dovranno ottenere la relativa "dispensa" della Santa Sede dalla norma generale che, a tenore dell'art. 124 della cost. ap. Pastor Bonus del 28 giugno 1988 [...], è di competenza del Tribunale della Segnatura Apostolica. Allo stesso Supremo Tribunale corrisponderà in tali casi approvare il tribunale di seconda istanza scelto dal Vescovo (can. 1438, $2^{\circ}$ CIC)» (PCITL, Chiarimenti, 13 ottobre 2015, prot. n. 15157/2015, en www.delegumtextibus.va); como se ve, partiendo del can. 20, el PCITL da una solución opuesta a la del Decano de la Rota romana: la ley universal posterior no deroga la ley particular anterior, salvo que expresa- 
del Rescripto ex audientia de 7-XII-2015 vino a acabar con dicho debate, afirmando el carácter derogador del Mitis Iudex respecto de cualquier «ley o norma contraria, general, particular o especial», también respecto del Qua cura de Pío XII ${ }^{5}$, aunque en puridad el efecto revocatorio pleno (abrogación) queda

mente lo prevea, o salvo que reordene íntegramente la materia; en consecuencia, habría que considerar vigente el status quo de los tribunales regionales en Italia, exigiéndose la autorización del STSA para que el obispo se «saliera» del tribunal regional; $3^{\circ}$ El definitivo Rescripto ex audientia de 7-XII-2015 -divulgado el 11 de diciembre de 2015-, firmado por el Papa Francisco y entregado al Decano de la Rota romana, en cuyo n. I indica lo siguiente al respeto de la cuestión que venimos comentando: «Las leyes de reforma del proceso matrimonial antes citadas abrogan o derogan toda ley o norma contraria hasta ahora vigente, general, particular o especial, eventualmente aprobada también en forma específica (como por ejemplo el Motu proprio Qua cura, dado por mi predecesor Pío XII en tiempos muy distintos a los actuales)» [FRANCISCO, Rescripto del Santo Padre Francisco sobre el cumplimiento y la observacia de la nueva ley del proceso matrimonial, 7 de diciembre de 2015, en vatican.va, 11-XII-2015, y en L'Osservatore Romano 155 (2015), 12-XII-2015, p. 8]; $4^{\circ}$ Recientemente habría que hacer referencia a la creación de una «mesa de trabajo» por el Papa Francisco para «la definizione delle principali questioni relative all'attuazione in Italia della reforma del processo matrimoniale», coordinada por el Secretario de la CEI, y con la participación de Mons. Pio Vito Pinto -el Decano de la Rota Romana-, el Card. Dominique Mamberti -el Prefecto del STSA- y el Card. Francesco Coccopalmerio -Presidente del PCITL-; la primera reunión fue el 6 de julio de 2016, cuyas primeras conclusiones relacionadas con la cuestión que estamos tratando son las siguientes: «- Il Motu Proprio prevede che "Il Vescovo costituisca per la sua diocesi il tribunale diocesano per le cause di nullità del matrimonio, salva la facoltà per lo stesso Vescovo di accedere a un altro viciniore tribunale diocesano o interdiocesano" (can. 1673, \$2). Il Vescovo che intende recedere dal tribunale regionale o interdiocesano di appartenenza lo comunica agli altri Vescovi interessati e al Supremo Tribunale della Segnatura Apostolica. La Segnatura verifica e attesta la sussistenza delle condizioni per un adeguato funzionamento delle strutture giudiziarie. Anche nelle diocesi più piccole, il tribunale diocesano deve avere almeno un giudice chierico, un difensore del vincolo e un notaio; - La costituzione dei tribunali interdiocesani all'interno della stessa metropolia è libera, con comunicazione alla Segnatura Apostolica; La costituzione dei tribunali interdiocesani costituiti da diocesi appartenenti a metropolie o provincie ecclesiastiche differenti richiede la licenza della Segnatura Apostolica; - Nel caso di recesso dal tribunale regionale di una o più diocesi, i Vescovi che intendano continuare ad avvalersi del medesimo tribunale emettono un decreto di erezione della nuova istituzione, approvandone il regolamento e cambiandone la denominazione (da regionale a interdiocesano)» (CONFERENZa EPISCOPALE ITALIANa, Segreteria Generale, Il testo frutto del «Tavolo di lavoro», 20-VII-2016: http://www.chiesacattolica.it/pls/cci_new_v3/v3_s2ew_consultazione. redir_allegati_doc?p_id_pagina=83478\&p_id_allegato=99701\&rifi=guest\&rifp=guest\&p_url_ rimando=\%2Fcci_new_v3\%2Fallegati\%2F83478\%2FTavolo\%20di\%20lavoro.pdf).

${ }^{5} \mathrm{Al}$ menos en lo que se refiere a cuestiones como la prohibición de establecer tribunales diocesanos matrimoniales y la imposición de tribunales regionales, lo que no comporta la abolición de los tribunales regionales existentes; ése es el parecer que se expresa en el votum periti unido a la carta del STSA de 22 de diciembre de 2015 dirigida al Secretario General de la CEI, quien solicitó el parecer del STSA a propósito de la competencia de los tribunales regionales en Italia (STSA, Votum periti allegato alla lettera del 22 dicembre 2015, prot. n. 51232/12 VAR, en www.chiesacattolica.it). En efecto, los aspectos claves y la disciplina sobre la relación obispo diocesano-tribunal interdiocesano quedarían en los siguientes términos: $1^{\circ}$ Obligación del obispo diocesano de constituir tribunal (can. $1673 \$ 2$ ), de ahí que se inste a procurar «cuanto antes» la formación ne- 
subordinado a la subsistencia de una ley anterior absolutamente contraria a la ley universal posterior.

Muy relacionado con lo anterior, otra cuestión que se ha suscitado aunque con un posicionamiento doctrinal más pacífico es el de la vigencia de la Instrucción Dignitas Connubii. Éste es el tema sobre el que se nos ha propuesto reflexionar, y sobre el que circunscribimos nuestro análisis, que versará en torno a los siguientes aspectos: partiremos de la consideración de Mitis Iudex desde la lógica de la continuidad procesal, haremos posteriormente una aproximación a la naturaleza normativa de la Dignitas Connubii y a la vigencia de la misma a la luz del can. $1691 \$ 3$, y concluiremos con la afirmación del valor hermenéutico de la Instrucción Dignitas Connubii más allá de su vigencia normativa.

\section{El M. P. Mitis IUDEX Y LA LÓGICA DE LA CONTINUIDAD PROCESAL}

El espíritu informador de M. P. Mitis Iudex, tal como se indica igualmente en el Proemio, es «"el enorme número de fieles que, aun deseando proveer a su propia conciencia, con demasiada frecuencia quedan apartados de las estructuras jurídicas de la Iglesia a causa de su distancia física o moral"; por tanto, la caridad y la misericordia exigen que la misma Iglesia se haga accesible a los hijos que se consideran separados». Éste es el espíritu que subyace a la extraordinaria reforma del proceso de nulidad realizada por el Papa Francisco, reforma que debe ser encuadrada en esa aportación carismática del munus petrino en una época de cambios y de profunda transformación ${ }^{6}$, época en la que la

cesaria de los futuros miembros (art. $8 \$ 2 \mathrm{RP}$ ); $2^{\circ}$ De acuerdo con el art. $8 \$ 2 \mathrm{RP}$, el obispo diocesano puede «abandonar» libremente el tribunal interdiocesano, no requiriendo para ello de la autorización de ninguna instancia superior, tampoco del STSA; $3^{\circ}$ El M. P. Mitis Iudex salvaguarda las estructuras judiciales intediocesanas anteriores a la entrada en vigor, también los tribunales interdiocesanos (también el rescripto de 7-XII-2015); $4^{\circ}$ El Mitis Iudex no prevé la constitución de nuevos tribunales interdiocesanos en un futuro, más aún, el can. $1673 \$ 2$ parece oponerse a la creación ex novo de dichos tribunales; sin embargo, por razones de sano realismo eclesial, y aplicando el criterio de subsidiariedad, se puede concluir que la creación de nuevos tribunales interdiocesanos entra dentro del derecho del obispo a organizar con libertad la administración de justicia [cfr. C. M. Morán Bustos, Criteri organizzativi dei tribunal e criteri d'azione degli operatori giuridici dopo la promulgazione del M. P. Mitis Iudex, en H. FranCESCHI - M. Á. ORTIZ (eds.), Ius et matrimonium II. Temi processuali e sostanziali alla luce del Motu Proprio Mitis Iudex Dominus Iesus. Subsidia Canonica 21, Roma 2017, 125-127].

${ }^{6}$ De ahí que comparta el siguiente parecer: «Un atteggiamento scettico o di riserva nell'applicazione della riforma tradisce invero una grave mancanza di onestà intellettuale e di lealtà deontologica. Il possibile affinamento della normativa e la perfettibilità del mezzo tecnico non sono un ostacolo o una remora alla collaborazione e all'impegno, ma semmai un incentivo alla giurispru- 
Iglesia -guiada por la intuición del Papa Francisco- debe hacer efectiva esa verdadera «conversión de las estructuras» a la que se refiere el Santo Padre en el n. 27 de la Evangelii Gaudium, también de las jurídicas ${ }^{7}$. La lógica del M. P. Mitis Iudex es la de esta conversión-reforma de las estructuras, lo cual nos sitúa lejos del inmovilismo, pero también lejos de la de ruptura o de la discontinuidad.

Más allá de las novedades -algunas de ellas de calado ${ }^{8}$, lo cierto es que hay que hacer una interpretación de la reforma desde una lógica de continuidad procesal, no por voluntarismo o por posicionamiento doctrinal ad boc, sino porque no se puede dudar de que, por lo que se refiere a los principios conformadores del proceso de nulidad, existe una continuidad respecto de la anterior configuración del proceso, cuyos fundamentos esenciales permanecen inalterados; a saber: la búsqueda de la verdad -el favor veritatis y favor matrimonii- y la protección de la indisolubilidad del vínculo conyugal, la afirmación de la naturaleza declarativa del proceso de nulidad y del pronunciamiento final, la vinculación de los procesos de nulidad a la potestad judicial, la protección y garantía del contradictorio procesal y del ius defensionis, la libre valoración de las pruebas y la necesidad de certeza moral, y la consideración de la misma en continuidad con el magisterio pontificio y la protección del ius apellandi.

El proceso de nulidad es más que un conjunto de canónes articulados, tiene una historia ${ }^{9}$ y una ratio ${ }^{10}$, y la reforma del Papa Francisco está en con-

denza e alla dottrina a migliorare l'ordinamento processuale del settore attraverso la prassi e la speculazione» (cfr. M. Del Pozzo, L'organizzazione ecclesiastica alla luce del M. P. Mitis Iudex, en www.statoechiese.it 36/201, noviembre 2015, 31).

7 Cfr. C. M. Morán Bustos, Retos de la reforma procesal de la nulidad del matrimonio, Ius Canonicum 56 (2016) 10-16.

${ }^{8}$ Por ejemplo vid. O. DE BerTOLIs, Papa Francesco riforma il processo canonico matrimoniale, La civiltà cattolica $166(2015 / \mathrm{IV}) 59$.

${ }^{9}$ La institucionalización de este instrumento de justicia que es el proceso representa una progresiva conquista de civilización y de respeto por la dignidad del hombre, a la que ha contribuido de una forma notable la misma Iglesia con el proceso canónico. Al hacer esto, la Iglesia no ha renegado de su misión de caridad y de paz, sino que solamente ha preparado un medio adecuado para aquella constatación indispensable de la justicia animada por la caridad. El hombre no conoce otro medio para alcanzar la verdad y para realizar la justicia cuando existe un conflicto, tampoco el fiel: ejercicio del derecho a la tutela judicial efectiva (reconocido como derecho fundamental del fiel por el can. 221), necesidad de un órgano juzgador imparcial, recurso a los medios de prueba, ejercicio del ius defensionis, mecanismos de valoración libre y objetiva de las pruebas, necesidad de certeza moral, posibilidad de apelar..., he aquí algunos de los instrumentos procesales indispensables para conocer la verdad y realizar la justicia. De ellos se ha servido históricamente la Iglesia, y en continuidad con ellos está la reforma del M. P. Mitis Iudex.

${ }^{10}$ La ratio última del proceso tiene que ver con esa dimensión de justicia que forma parte integral de la relación objetiva en que consiste el matrimonio, pues «la quidditas de la comunidad de vida 
tinuidad con ambas. Por ello, la relación entre la reforma introducida y la normativa procesal anterior no puede ser vista ni interpretada en términos de confrontación, de oposición o de ruptura, sino en términos de «integración recíproca» ${ }^{11}$.

En este sentido, ni cabe recibir la reforma con prejuicios, rasgándose las vestiduras, con una actitud inmovilista, con resistencia enfurecida al cambio, ni tampoco con laxismo, rompiendo los criterios uniformes de la jurisprudencia canónica, haciendo de cada tribunal una especie de «isla» o de «mónada» en el conjunto de estructura judicial de la Iglesia, rebajando el nivel y la calidad de las instrucciones y de los pronunciamientos, todo ello bajo el «cobijo» de la supresión de la necesidad de un doble pronuncimiento por parte de otro tribunal superior. Si así se hiciera, se malograría esa opción que el M. P. Mitis Iudex hace por la confianza, la responsabilidad y la autonomía de cada tribunal -y en definitiva, de cada uno de los operadores jurídicos-, y se frustaría una reforma que, si bien es verdad que pone el acento más en el acceso a los tribunales y en la celeridad del pronunciamiento que en el control y la verificación de lo decidido, tiene como ratio y fundamento último la búsqueda de la verdad y la protección de la indisolubilidad ${ }^{12}$.

y amor indisolublemente fiel y fecunda, en que consiste el matrimonio, es un vínculo de naturaleza jurídica, sin el cual una unión entre un varón y una mujer sería mera convivencia sexual de hecho, pero no matrimonio. La naturaleza real de ese vínculo, que es de justicia y, por ello, jurídico, hace que su comprensión y manifestación más específica corresponda al valor jurídico de la Iglesia, o, lo que es lo mismo, a la expresión canónica... No son los canonistas quienes le han impuesto a la esencia del matrimonio un vínculo jurídico. Ocurre al revés: es la real naturaleza de justicia del vínculo matrimonial la que exige específicamente manifestarse en términos jurídicos» [P. J. VILADRICH, Matrimonio y sistema matrimonial de la Iglesia. Reflexiones sobre la misión del derecho matrimonial canónico en la sociedad actual, Ius Canonicum 54 (1987) 508]. Es en esta juridicidad del matrimonio, que es intrínseca a ese consortium totius vitae en que consiste el matrimonio, que pertenece a la misma esencia de lo que es esa «comunidad de vida y amor», en donde se encuentra en última instancia la ratio de un proceso como el de nulidad del matrimonio, proceso que tiende a buscar, proteger y defender la ontología del matrimonio, su verdad y su justicia, pues -como afirmaba Benedicto XVI en 2007- «en las causas de nulidad matrimonial la verdad procesal presupone la "verdad del matrimonio" mismo», verdad que «pierde relevancia existencial en un contexto cultural marcado por el relativismo y el positivismo jurídico, que consideran el matrimonio como una mera formalización social de los vínculos afectivos» (BENEDICTO XVI, Discurso a la Rota romana de 27 de enero de 2007, en www.iuscanonicum.org).

${ }^{11}$ Cfr. M. DEL Pozzo, L'impatto della riforma sul diritto processuale vigente, Associazione Canonistica Italiana, Udine, settembre 2016, en vías de publicación, $\$ 1,1$.

12 Así aparece claramente en el Proemio: «con el transcurrir de los siglos, la Iglesia, en materia matrimonial, adquiriendo conciencia más clara de las palabras de Cristo, ha comprendido y expuesto más profundamente la doctrina sobre la indisolubilidad de vínculo del matrimonio, ha elaborado el sistema de la nulidad del consentimiento matrimonial y ha disciplinado más ade- 
Por tanto, afirmar que el M. P. Mitis Iudex sigue la lógica de la continuidad procesal es afirmar que las instituciones procesales siguen siendo subsidiarias e instrumentales respecto de la búsqueda de la verdad del vínculo conyugal y de la protección de su indisolubilidad; y si esto es así a nivel legislativo, también a nivel de la praxis forense concreta -de la actuación de cada uno de los operadores jurídicos- se debe tender a ello de modo irrenunciable ${ }^{13}$; en caso contrario, estaríamos en la lógica de la discontinuidad y de la ruptura, que no tienen cabida alguna en la reforma procesal del Papa Francisco.

Más allá de que los nuevos cann. 1671-1691 vienen a sustituir a los anteriores referidos al proceso de nulidad del matrimonio, existe una continuidad que se concreta, no sólo en las múltiples referencias a disposiciones del CIC $83^{14}$, sino en la necesidad de reconducirse constantemente a lo establecido para los procesos en general y para el contencioso-ordinario en particular, ello al amparo del can. $1691 \$ 3$ y del art. 6 de la Ratio Procedendi; en esta lógica de la continuidad, y en estas fuentes normativas, es donde hay que colocar la reflexión sobre la vigencia y el valor de la Dignitas Connubii.

\section{El nuevo Can. $1691 \$ 3$ y la Dignitas ConNubiI: NATURAlEZa NORMATIVA DE LA INSTRUCCIÓN Y VIGENCIA DE LA MISMA}

A primera vista, podría pensarse que la Instrucción Dignitas Connubii habría quedado en una posición «singular», sin vigencia, de modo que ninguno de los 308 artículos que la componen tendrían ya un carácter vincu-

cuadamente el proceso judicial sobre dicha materia, todo ello de acuerdo con la verdad de fe profesada... Consciente de ello, establecí que se iniciara la reforma de los procesos de nulidad del matrimonio... salvando siempre el principio de la indisolubilidad del vínculo matrimonial». Ésta es la ratio que subyace a estas Normas, y ésta es la razón por la que se ha querido vincular estas causas a la potestad judicial, y no a la administrativa, y por este mismo razón -proteger la indisolubilidad del matrimonio- viene justificada la intervención del obispo en los procesos breves, de hecho así se indica textualmente en el Proemio.

13 Como ha afirmado recientemente el Papa Francisco, «亡̀ importante che la nuova normativa sia recepita e approfondita, nel merito e nello spirito, specialmente dagli operatori dei Tribunali ecclesiastici, per rendere un servizio di giustizia e di carità alle famiglie. Per tanta gente, che ha vissuto un'esperienza matrimoniale infelice, la verifica della validità o meno del matrimonio rappresenta un'importante possibilità» (FRANCISCO, Discorso ai partecipanti al corso promosso dal Tribunale della Rota romana, 12 marzo 2016, en www.vatican.va).

${ }^{14}$ Por orden, en los cann. 1671-1691 se citan los siguientes cánones del CIC 83: 1752, 1438-1439, 1444, 1518, 1559, 1574, 1630-1633, 1619-1640, 1644, 1504, 1656-1670; en el articulado de la Ratio Procedendi se citan los siguientes: $383 \$ 1,529 \$ 1,1418,1423$. 
lante. Como fundamento de esta conclusión inicial cabría invocar básicamente dos argumentos: en primer lugar, el silencio del M. P. Mitis Iudex respecto de la persistencia de la Dignitas Connubii, así como la ausencia de referencia o de cita alguna a la misma tanto en los 21 canónes que conforman la nueva ley, como en los 21 artículos de la Ratio Procedendi-que también tienen naturaleza legislativa ${ }^{15}-$, y el propio Proemio de la norma; alguno podría pensar que con este silencio, el Papa Francisco habría abrogado la Dignitas Connubii.

En segundo lugar, cabría invocar el can. $34 \$ 3$, según el cual, «las instrucciones dejan de tener valor no sólo por revocación explícita o implícitamente de la autoridad competente que las emitió, o de su superior, sino también si cesa la ley para cuya aclaración o ejecución hubieran sido dadas»; de acuerdo con ello, la Instrucción Dignitas Connubii habría quedado sin efecto en aplicación de dicho canon, pues habiendo sido sustituidos los anteriores canónes 1671-1691 que regulaban el proceso declarativo de la nulidad del matrimonio, y existiendo una reorganización de dicho proceso ${ }^{16}$, cesaría la Instrucción que se dio en aplicación-desarrollo de la citada normativa.

En mi opinión, no obstante esta inicial apariencia, la cuestión de la vigencia de la Dignitas Connubii no es tan simple, ni se puede afirmar que estos argumentos sean ni mucho menos definitivos.

Por lo que respecta al silencio del legislador, creo que el mismo se explica en parte teniendo en cuenta el principio de jerarquía normativa ${ }^{17}$, de hecho, sí que hay varias normas del M. P. Mitis Iudex que están tomadas li-

15 Vid. E. BAURA, Il valore normativo dell'Istruzione «Dignitas Connubii», en P. A. BONNET - C. GULLO (eds.), Il giudizio di nullità matrimoniale dopo l'Istruzione «Dignitas Connubii». Parte prima: I principi, Città del Vaticano 2007, 207; J. Herranz, Natura e finalità dell'Istruzione «Dignitas Connubii», en J. I. ARRIETA (ed.), L'Istruzione Dignitas Connubii nella dinamica delle cause matrimoniali, Venezia 2006, 13; J. OTADUY, El principio de jerarquía normativa y la Instrucción Dignitas Connubii, Ius Canonicum 46 (2006) 83.

${ }^{16}$ Esto lo que indica expresamente en el Proemio del M. P. Mitis Iudex: «Todo esto oportunamente considerado, decreto y establezco que el Libro VII del Código de Derecho Canónico, Parte III, Título I, Capítulo I sobre las causas para la declaración de nulidad del matrimonio (cánones 1671-1691), a partir del día 8 de diciembre de 2015, sea integralmente sustituido como sigue...».

17 «Invero non c'e comunque da sorprendersi di tale "dimenticanza", essendo il Mitis Iudex una fonte di rango superiore: quelle di rango inferiore seguono la "sorte" delle leggi per la cui esecuzione sono state date, anche qualora non siano menzionate in queste ultime» [G. BONI, La recente riforma del processo di nullità matrimoniale. Problemi, criticità, dubbi. dubbi (parte prima: SSS 13), Stato, Chiese e pluralismo confessionale. Rivista telemática 9 (2016) 44, nota 124 (http:// www.statoechiese.it/ 7 marzo 2016)]. 
teralmente de la Dignitas Connubii, por ejemplo los arts. 9 y 12 de la Ratio Procedendi (repiten literalmente los arts. 143, $1^{\circ}$ y $247 \$ 2$ de la Dignitas Connubii): el hecho de que, desde el punto de la naturaleza normativa, el M. P. Mitis Iudex tenga rango de ley, mientras que la Instrucción Dignitas Connubii sea una norma de naturaleza administrativa, podría explicar en parte este silencio, pues quizás no se ha querido citar una norma anterior de rango inferior. Sea como fuere, no creo que este silencio se pueda interpretar como expresión de una voluntad derogatoria total del legislador, ni tampoco como si con ello se pretendiera ningunear o hacer tabula rasa de una norma tan extensa en artículos y materias tratadas como la Dignitas Connubii. Desde luego, ésta no es la intención del Papa Francisco, como lo demuestran las palabras que él mismo dirigía el 24 de enero de 2015 a los participantes en el Congreso Internacional organizado por la Facultad de Derecho Canónico de la Pontificia Universidad Gregoriana; entonces, cuando -recordemosla Comisión encargada de la reforma del proceso de nulidad estaba trabajando ya durante varios meses en dicha reforma, y cuando faltaban menos de 6 meses para la firma del M. P. Mitis Iudex (15-VIII-2015), el Papa Francisco afirmaba lo siguiente a propósito del valor-servicio de la Instrucción Dignitas Connubii:

«La amplia participación en este encuentro indica la importancia de la Instrucción Dignitas Connubii, que no está destinada a los especialistas del derecho, sino a los agentes de los tribunales locales: es, en efecto, un modesto pero útil vademécum que toma realmente de la mano a los ministros de los tribunales con el fin de desarrollar un proceso que sea al mismo tiempo seguro y veloz. Un desarrollo seguro porque indica y explica con claridad la meta del proceso mismo, o sea la certeza moral: ella requiere que quede totalmente excluida cualquier prudente duda positiva de error, aunque no está excluida la mera posibilidad de lo contrario (cfr. Dignitas Connubii, art. 247, 2). Un desarrollo veloz porque -como enseña la experiencia común-camina más rápidamente quien conoce bien el camino que hay que recorrer. El conocimiento y diría la familiaridad con esta instrucción podrá también en el futuro ayudar a los ministros de los tribunales a abreviar el itinerario procesal, percibido por los cónyuges a menudo como largo y fatigoso. Hasta ahora no ban sido explorados todos los recursos que esta instrucción pone a disposición para un proceso veloz, carente de todo formalismo (...); tampoco se pueden excluir 
en el futuro ulteriores intervenciones legislativas destinadas al mismo objetivo» ${ }^{18}$.

Como se ve, no sólo se hace una valoración positiva de la Dignitas Connubii -en cuanto modesta pero útil guía que lleva de la mano a los ministros de los tribunales, a fin de desarrollar un proceso al mismo tiempo seguro y veloz-, sino que, al tiempo que echa en falta una explotación de las posibilidades de la Instrucción, se refiere a la misma en términos de futuro, aludiendo expresamente al servicio que puede seguir ofreciendo en un futuro a los tribunales, ello al margen de «ulteriores intervenciones legislativas» futuras (entonces). No parece, por tanto, que la mens legislatoris sea la de obviar y prescindir absolutamente de la Dignitas Connubii.

Al margen de ello, ¿realmente se puede considerar la Instrucción Dignitas Connubii como una de las instrucciones a las que se refiere el can. 34? Sin entrar en la cuestión de la denominación de la norma del PCITL ${ }^{19}$, si atendemos a quiénes son los destinarios de la Instrucción Dignitas Connubii y cuál es su contenido, fácilmente se concluye que no se trata de una de las Instrucciones a que se refiere el can. 34. En efecto, una instrucción es una norma interna de la administración eclesiástica, por la cual «una autoridad superior indica a una autoridad de menor rango que cumpla una ley, o le ofrece indicaciones para aclarar prescripciones de la ley que debe cumplir o hacer cumplir, o determina el modo en que debe ejecutarse la ley» ${ }^{20}$. Si nos fijamos en los destinatarios, a diferencia de lo que acontece con los decretos ejecutorios (can. 31) -que son las otras normas administrativas ejecutorias o de desarrollo-, que obligan a los que obligan las leyes cuyas condiciones de ejecución determinan o cuya observancia urgen (can. 32), los destinatarios de las instrucciones son «aquellos a quienes compete cuidar que se cumplan las leyes, y les obligan para la ejecución de las mismas»; en el caso de la Dignitas Con-

${ }^{18}$ FrancisCo, Discurso ai partecipanti al Congresso Internazionale promosso dalla Facoltà discreción de juicio acerca de los derechos que mutuamente se han de dar y aceptar en el Diritto Canonico della Pontificia Unviersità Gregoriana, AAS 107 (2015) 192; la traducción y la cursiva son nuestros.

19 Cfr. G. P. MontinI, L'istruzione «Dignitas Connubii» sui processi di nullità matrimoniale. Una introduzione, Quaderni di Diritto Ecclesiale 18 (2005) 342-363; IDEM, L'istruzione «Dignitas Connubii» nella gerarchia delle fonti, Periodica de re Canonica 94 (2005) 417-476; J. OTADUY, El principio de jerarquía normativa y la Instrucción «Dignitas Connubii», en R. RODRíGUEZ OCAÑA - J. SEDANo (eds.), Procesos de nulidad matrimonial. La Instrucción «Dignitas Connubii», Pamplona 2006, 45-80; J. Llobell, El valor jurídico de la instr: «Dignitas Connubii», su recepción eclesial, el objeto y la conformidad de la sentencia, y la certeza moral, en ibid., 235-301.

20 J. OTADUY, El principio de jerarquía normativa y la Instrucción «Dignitas Connubii»..., cit., 56. 
nubii, es evidente que no se dirigía sólo a quienes cuidaban que se cumplieran las leyes, ni tan siquiera -como se dice en el Proemio- «a los jueces y demás ministros del tribunal», sino que es una norma que afecta a todos aquellos que intervienen en el proceso ${ }^{21}$ y en cuanto tal, potencialmente a cualquier fiel.

Si descendemos al contenido de la Instrucción, parece también evidente que no estamos ante una norma que se limitara a aclarar, desarrollar o urgir el cumplimiento de un precepto determinado, sino que se trató de una verdadera reordenación del proceso de nulidad del matrimonio ${ }^{22}$, de modo que se coordinara y se hiciera más asequible una regulación compleja, que estaba diseminada y dispersa en varios pasajes del CIC, en concreto, en los cánones iniciales del libro VII, en las cánones del juicio contencioso y en los cánones ya específicos del proceso de nulidad ${ }^{23}$. Por tanto, aunque formalmente se denominó «Instrucción», no se puede decir que haya un equilibrio entre el contenido de la misma y una supuesta condición de norma administrativa: es obvio que no se limitó a aclarar las disposiciones sobre los procesos de nulidad previstas en los cann. 1671-1691, sino que incorporó unas normas de contenido muy heterogéneo: por ejemplo, incorporó los criterios de los discursos del Papa a la Rota romana, o las interpretaciones realizadas por el PCITL o por la misma jurisprudencia de los tribunales apostólicos (tanto de la Rota romana como de la Signatura apostólica), incluso algunos criterios de normas como la Lex Propria de la Rota romana o las normas del Tribunal de la Rota de la Nunciatura ${ }^{24} .$. No siendo una norma exclusivamente aclaratoria ni de desarrollo-ejecución, no parece que se le pueda aplicar a la Instrucción Dignitas Connubii el criterio del can. $34 \$ 3$-ni tampoco el criterio del can. $33 \$ 1-$, y en cuanto tal, no se puede afirmar que haya dejado «de tener fuerza».

En realidad, si miramos el M. P. Mitis Iudex no encontramos en él una revocación explícita de la Dignitas Connubii, ni tampoco se puede hablar de

${ }^{21}$ Cfr. J. GOnZÁlez AyesTa, Valor jurídico de la Instrucción Dignitas Connubii en el marco del sistema normativo canónico de fuentes del derecho, en R. ROdRÍGUEZ CHACóN - L. RuANo Espina (eds.), Los procesos de nulidad de matrimonio canónico, Madrid 2006, 28-29.

${ }^{22}$ R. Rodríguez Chacón, Antecedentes, estructura y valor jurídico en el sistema normativo canónico de los dos Motu Propio de 15 de agosto de 2015 y sus normas anejas, en M. E. Olmos OrTega (ed.), Procesos de nulidad matrimonial tras la reforma del Papa Francisco, Madrid 2016, 55.

23 Vid. F. DaneELs, Una introducción general a la Instrucción Dignitas Connubii, en R. RodrígueZ OcaÑa - J. Sedano (eds.), Procesos de nulidad matrimonial. La Instrucción..., cit., 28.

${ }^{24}$ Cfr. J. Llobell, El valor jurídico de la instr. «Dignitas Connubii»..., cit., 238. 
una revocación implícita general, que sólo se establece respecto de las normas anteriores que sean contrarias a las nuevas disposiones normativas («contrariis quibusvis, etiam specialissima mentione dignis, non obstantibus»). En efecto, la fórmula revocatoria general que se contiene en el n. VIII del Proemio se aplica a los anteriores cánones reguladores del proceso nulidad del matrimonio, «sustituidos íntegramente» por los nuevos cann. 16711691 (y por los artículos de la Ratio Procedendi); en relación con éstos, además de existir esta referencia expresa derogatoria, estaríamos ante un supuesto de revocación por ordenación íntegra de la materia al que se refiere el can. 20: una ley posterior que abroga o deroga la precedente, no sólo en lo que se establezca de modo expreso, ni sólo en lo que sea contrario, sino también en la medida en que hay una reordinación integral de las anteriores disposiciones legales. En relación con ello, el profesor Rodríguez-Chacón considera que lo que se ha producido es una «obrogatio parcial» de la ley procesal anterior: distinta de la derogatio, que alude al caso en que una norma anterior queda sólo parcialmente sin efecto, y también de la abrogatio, que recoge el supuesto de una norma que deja sin efecto totalmente otra norma anterior, la obrogatio vendría a ser aquel supuesto en el que la ley no se limita a dejar sin efecto parcial o totalmente otra anterior, sino que además viene a sustituir a la misma. En el caso del M. P. Mitis Iudex, se habría producido lo que él llama una «obrogación parcial», pues lo que se ha establecido «no comporta una nueva regulación completa o global de los procesos para la declaración de nulidad del matrimonio sino sólo de las especialidades propias de esa clase de procesos que se contienen en el capítulo I del título I, de la parte III del libro VII del CIC» ${ }^{25}$, alguna de las cuales hasta un total de 12 reproducidas sustancialmente con los mismos textos que se contenían en los cánones sustituidos ${ }^{26}$.

Precisamente por ello, porque como indica el art. 6 de la Ratio Proceden$d i$ «las presentes normas no pretenden exponer pormenorizadamente la totalidad del proceso, sino, sobre todo, esclarecer las innovaciones legislativas principales y, en su caso, integrarlas», es por lo que se hace absolutamente necesario acudir de modo constante a lo regulado en el CIC 83 respecto de los

${ }^{25}$ R. RodríGUEz CHACÓN, Antecedentes, estructura y valor jurídico en el sistema normativo canónico..., cit., 43.

${ }^{26}$ En realidad, la sustituación es más formal que sustantiva, de hecho son varias las coincidencias sustantivas en algunos casos literales entre los nuevos cánones y los canónes sustituidos. 
procesos en general. Pues bien, es aquí donde encuentra fundamento la tesis de la vigencia de la Dignitas Connubii, vigencia que será «parcial», pues tendrá los límites de la subordinación a la nueva ley ${ }^{27}$.

En efecto, este reenvío a lo dispuesto en los procesos en general y el juicio contencioso ordinario en particular está realizado de modo expreso por el can. $1691 \$ 3$ : «en todas las demás cosas que se refieren al procedimiento, si no lo impide la naturaleza del asunto, aplíquense los cánones sobre los juicios en general y sobre el juicio contencioso ordinario, cumpliéndose las normas especiales para las causas acerca del estado de las personas y para aquellos que se refieren al bien público». Este nuevo can. $1691 \$ 3$ reproduce literalmente el anterior can. 1691, el cual, a su vez, fue considerado por la doctrina como el fundamento legal de la Dignitas Connubii; de hecho, se partió de él para habilitar jurídicamente las modificaciones, silencios, recortes o añadidos de la Instrucción respecto de las normas codiciales sobre el proceso de nulidad del matrimonio ${ }^{28}$ : todo ese contendido, que ciertamente escapaba a la idea general de «aplicar y desarrollar» propia de las instrucciones, tenía su fundamento en el can. 1691, el cual, a su vez, respondía a la idea de adaptar las normas del proceso ordinario a la naturaleza propia de los procesos matrimoniales, en concreto, a su carácter público -relacionado con el bien público de la Iglesia-, personal -tiene que ver con el estado de las personas y con el bien de sus almas-, y no contencioso -tiene un carácter declarativo- que tiene el proceso matrimonial ${ }^{29}$. Según palabras del Papa Benedicto XVI en su primer discurso a la Rota romana, en esto consistía precisamente la mayor aportación de la Instrucción: «la Dignitas Connubii... no sólo recoge las normas vigentes en esta materia, sino que las enriquece con ulteriores disposiciones, necesarias para la correcta aplicación de las primeras. La contribución más importante de la Instrucción, que deseo que sea

27 Cfr. J. Llobell, Alcune questioni comuni ai tre processi per la dichiarazione di nullità del matrimonio previsti dal M. P. «Mitis Iudex», Ius Ecclesiae 28 (2016) 18; IDEM, Quelques questions communes aux trois procès pour la déclaration de nullité du mariage prévus par le motu proprio «Mitis Iudex», en E. CAPARros - L. NAVARRO - Th. Sol (eds.), La réforme opérée par le M. P. «Mitis Iudex». Commentaires et documentation. Actes d'un colloque organisé par LUMSA Università et Consociato Internationalis Studio Iuris Canonici Promovendo, Rome, 30 novembre 2015, Montréal-Paris 2016, 36.

28 Cfr. F. Daneels, Una introducción general a la Instrucción Dignitas Connubii..., cit., 29-35; J. LloBELL, El valor jurídico de la «Dignitas Connubii»..., cit., 243-244; G. P. MontinI, L'istruzione Dignitas Connubii..., cit., 423-426.

29 Cfr. J. OTADUY, El principio de jerarquía normativa y la Instrucción «Dignitas Connubii»..., cit., 64. 
aplicada íntegramente por quienes trabajan en los tribunales eclesiásticos, consiste en indicar en qué medida y en qué modo las normas contenidas en los cánones relativos al proceso contencioso ordinario deben ser aplicadas en las causas de nulidad matrimonial, observando las normas especiales dictadas para las causas sobre el estado de las personas y para aquéllas sobre el bien público» ${ }^{30}$. Pues bien, en la medida en que esas normas del proceso ordinario no han cambiado, esta misma puede seguir siendo la función-servicio de la Instrucción Dignitas Connubii.

Por tanto, en este can. $1691 \$ 3$ está el fundamento para seguir aplicando la Dignitas Connubii como exigencia de la necesidad de adaptar las normas del proceso ordinario a las nuevas normas de los procesos matrimoniales. Como se ha dicho, el límite de la aplicabilidad de Dignitas Connubii será el de las novedades y modificaciones introducidas por el M. P. Mitis Iudex. Así, en la medida en que algún artículo de la Instrucción entre en contradicción con la nueva ley habrá de entenderse derogado o sin efecto, y también cuando exista una modificación novedosa que tuviera antes reflejo en algún artículo de la Instrucción. Esto es lo que ocurre en los siguientes supuestos y con los artículos concretos que sigue ${ }^{31}$ :

- El nuevo can. 1672 referido a los títulos de competencia reordena íntegramente la materia del antiguo can. 1673 de hecho es una de las novedades más relevantes, de modo que se han de considerar revocados los arts. $10 \$ \$ 1$ y 13; por lo que respecta al nuevo foro de «cuasidomicilio» de las partes ${ }^{32}$, en sí mismo es una norma que fácilmente posibilitará una praxis muy distinta de lo que recomienda el art. 7 de la Ratio Procedendi (principio de proximidad entre el juez y las partes, «en cuanto sea posible»).

- El nuevo can. 1673 contiene una serie de disposiciones novedososas en sus $\$ \$ 2-5^{33}$ que comportan una derogación de las normas para-

30 Benedicto XVI, Discurso a la Rota romana de 28 de enero de 2006, en www.iuscanonicum.org.

31 Cfr. W. L. Daniel, An Analysis of Pope Francis' 2015 Reform of the General Legislation Governing Causes of Nullity of Marriage, The Jurist 75 (2015) 461-464.

32 Cfr. C. M. Morán Bustos, Criteri organizzativi dei tribunal e criteri d'azione degli operatori giuridici dopo la promulgazione del M. P. Mitis Iudex..., cit., 133-134.

33 Por lo que respecta al can. $1673 \$ 1$, al hablar de que el obispo «puede ejercer la potestad judicial por sí mismo o por medio de otros», lo que ha hecho es deslizar la balanza hacia el lado del obispo diocesano, de modo que se venga a corregir una extendida y casi crónica desatención por parte de los obispos diocesanos respecto de la actuación de sus tribunales. En este sentido, lo que 
lelas del CIC 83 que podríamos considerar «parcial», en el sentido de que, sin bien siguen teniendo vigencia para los procesos en general, no son ya de aplicación para los procesos de nulidad del matrimonio. Así ocurre, por ejemplo, con los siguientes supuestos: $1^{\circ}$ En el nuevo can. $1673 \$ 3$, que introduce la novedad de permitir a los laicos actuar como jueces, ello sin el requisito del permiso de la Conferencia Episcopal (el can. $1421 \$ 2$ ), lo que comporta la derogación, no del can. 1421 $\$ 2$ en sí -que sigue teniendo aplicación para el resto de procesos, en los que seguirá siendo necesario el permiso de la Conferencia Episcopal para poder nombrar jueces laicos- sino de la aplicación de este requisito al nombramiento de jueces laicos para los procesos de nulidad, algo a lo que se refiere el art. $43 \$ 2 \mathrm{DC}$, que en cuanto tal sí que queda derogado. $2^{\circ}$ En apelación, el can. $1673 \S 5$ establece la colegialidad como necesaria («para la validez»), pudiéndo estar formado este colegio por dos jueces laicos, para lo cual de acuerdo con la remisión que hace al $\$ 3$ no se ha de verificar ninguna situación excepcional o «de necesidad», ni se requiere de ningún permiso de la Conferencia Episcopal, algo que no podría acontecer en otros procesos, en los que si media el permiso de la conferencia episcopal y la situación de necesidad, sólo podrá ser laico uno de los jueces del tribunal de apelación (can. $1421 \$ 2$ ); $3^{\circ}$ Por lo que respecta a la posibilidad del tribunal monocrático en primera instancia, el can. $1673 \$ 4$ supone también una derogación «parcial» del can. 1425 $\$ 4$, en la medida en que se puede articular dicha hipótesis sin el permiso de la Conferencia Episcopal que seguirá siendo necesario para el resto de procesos, ello incluso bajo pena de nulidad de acuerdo con el can. $1622,1^{\circ}$, lo que comporta igualmente la derogación del art. $30 \$ 3$ DC. $4^{\circ} \mathrm{El} \$ 2$ a del can. 1673 y el art. $8 \$ \$ 1$ y 2 establecen el derechodeber del obispo de constituir su propio tribunal y el derecho a abando-

realmente se pretende es que el obispo diocesano se comprometa en el desarrollo de la función judicial, lo cual va mucho más allá del ejercicio inmediato de la función de juez. En relación con ello, sí que se puede hablar de una cierta inversión de la recomendación que hace art. $22 \$ 2$ de la Dignitas Connubii en línea con el can. 1420 CIC 83 de que el obispo diocesano «no actúe por sí mismo, salvo que haya causas especiales» que así lo justifiquen. Sin embargo, más allá de ese matiz, si nos atenemos a la literalidad del nuevo can. $1673 \$ 1$, se advierte fácilmente que lo que se hace es reproducir el criterio del can. 1419 y aplicarlo al ámbito del proceso de nulidad: ahora, como antes, se reconoce al obispo diocesano el derecho de actuar «por sí mismo» como juez, algo que en el proceso ordinario y en el proceso documental es una posibilidad, y que en el proceso brevior es una obligación (ésta sí que novedosa, porque todo el proceso brevior es novedoso en sí). 
nar el tribunal interdiocesano ${ }^{34}$, esto último sin necesidad de autorización de la Signatura Apostólica; pues bien, aunque no se alude a la creación ex novo de nuevos tribunales interdiocesanos, lo cierto es que en las citadas fuentes -y en el can. 1423 del CIC 83- está la base de dicha posibilidad, que se podría articular sin la necesidad de autorización de la Signatura Apostólica $^{35}$, lo que supone la derogación del art. $23 \$ 1$ de la Dignitas Connubii; $5^{\circ}$ Los $\$ \$ 2$ b y 4 del can. 1673 también vienen a derogar los arts. $24 \$ 1$ y $69 \$ 2^{36}$, pues se permite que al obispo diocesano -cuando no pueda constituir su tribunal, algo que se configura como una verdadera obligación en el can. $1673 \$ 2$ y en el art. $8 \$ 1$ Ratio Procedendi-acceder a un «tribunal cercano»-diocesano o interdiocesano-, ello sin necesidad de acudir a la prórroga de competencia por parte de la Signatura Apostólica. En la medida en que esta hipótesis no está prevista en el CIC 83, no parece que se pudiera aplicar a otros procesos distintos de los de nulidad del matrimonio ${ }^{37}$. En este supuesto, al igual que en los ante-

${ }^{34}$ Conocido es ya por todos el debate y la discusión extraordinaria que dicho art. $8 \$ 2$ ha suscitado. El debate se ha producido sobre todo en el ámbito italiano, teniendo como planteamiento de fondo la vigencia o no del M. P. Qua cura, y la propia subsistencia de los tribunales regionales creados, no al amparo del can. 1423 al que dicho artículo se refiere, sino bajo la citada norma de Pío XII. Los momentos principales de este debate se pueden ver en la nota 4.

35 La mens legislatoris distingue según que los obispos decididos a formar el nuevo tribunal interdiocesano pertenecieran o no a la misma provincia eclesiástica: si fueran de la misma provincia eclesiástica no se requeriría ni siquiera de la aprobación de la Sede Apostolica a la que se refiere el can. $1423 \$ 1$ ni el nibil obstant anterior, ni el control posterior, lo que parece ir contra la praxis de la propia Signatura Apostólica (art. 35 LP); si los obispos pertenecieran a provincias eclesiásticas distintas entonces sí que se necesitarían «licencia» de la Sede Apostólica: «I vescovi all'interno della provincia ecclesiastica possono liberamente decidere, nel caso non ravvedano la possibilità nell'imminente futuro di costituire il proprio tribunale, di creare un tribunale interdiocesano; rimanendo, a norma di diritto e cioè con licenza della Santa Sede, la capacità che metropoliti di due o più provincia ecclesiatiche possano convenire nel creare $\mathrm{i}$ tribunale interdiocesano sia di prima che di seconda istanza» [P. V. PINTO, Speranza e non paure. Intervista al decano della Rota romana sul nuovo processo matrimoniale, L'Osservatore Romano 155 (2015), 8 ottobre 2015, p. 7]; como se puede leer en la nota anterior, este mismo es el tenor de la nota publicada tras la primera reunión de la «mesa de trabajo» creada bajo coordinación de la CEI; como se ve, un parecer muy distinto, que quizás requeriría de un pronunciamiento interpretativo «auténtico» que cubriera el silencio del Mitis Iudex al respecto.

36 Vid. cfr. Z. Grocholewski, Sub can. 1420, cit., 733, nota 2; M. Del Pozzo, Dal «tribunale limitrofo» al «tribunale sussidiario»: una proposta di migliore sistematizazione concettuale della nozione, en J. KowAL - J. Llobell (eds.), Iustitiam et iudicium: studi di diritto matrimoniale e processuale canonico in onore di Antoni Stankiewicz, Città del Vaticano 2010, 1627-1644.

37 La hipótesis del «tribunal próximo» es una hipótesis no prevista en el CIC 83, y cuyo antecedente inmediato es el «tribunal próximo» («vicinum tribunal») del art. $24 \$ 1$ de la Dignitas Connubii, aunque a diferencia de éste, la posibilidad de acudir a un tribunal «cercano, o próximo o vecino»-diocesano o interdiocesano- por parte del obispo diocesano no está sujeta a la conce- 
riores, lo que se evidencia es la necesidad de armonizar la normativa general, quizás aplicando aquí con sentido positivo la llamada «matrimonialización» del derecho procesal, de modo que estos criterios que se establecen para el proceso de nulidad del matrimonio sean los criterios generales asumidos para los procesos en general y para el contencioso ordinario en particular ${ }^{38}$, a lo sumo, salvando algunas situaciones especiales (por ejemplo, algunas especialidades relacionadas con la peculiariedad y especificidad del proceso penal).

- El can. 1675, al sustituir al anterior can. 1676 y poner el acento en la constatación «de que el matrimonio haya fracasado irreparablemente» ${ }^{39}$, deroga el art. $65 \$ 1$, que -en línea con el canon que desarro-

sión de la prórroga de competencia -que supla la incompetencia relativa- por parte de la Signatura Apostólica (art. 124, $3^{\circ} \mathrm{PB}$ ); en realidad, esta «habilitación» de la Sede Apostólica se habría de entender concedida implícitamente en virtud del propio can. $1673 \$ 2$, con lo que se evitan los interrogantes «eclesiológicos» relacionados con el ejercicio por parte del obispo de la potestad judicial extra territorium; lo que la norma no hace de ninguna manera es suplir la incompetencia absoluta, de ahí que no se podría designar como «tribunal vecino-cercano» uno que fuera incompetente ratione obiecti o por razón del grado (art. $9 \$ 1,2^{\circ} \mathrm{DC}$ ), pues estaríamos ante un supuesto de incompetencia absoluta que requeriría de comisión de competencia del STSA (art. $9 \$ 3 \mathrm{DC}$, art. $124,3^{\circ} \mathrm{PB}$, arts. $35,2^{\circ}$ y $115 \$ \$ 1-2$ LPSTSA).

38 En este sentido comparte el siguiente parecer del profesor Del Pozzo: «La "matrimonializzazione" di fatto dell'ordinamento giudiziario implica però che sia improponibile e irragionevole alla lunga un regime disociativo o parallelo. La reforma com'è noto a inciso considerevolmente e in maniera costitutiva sull'apparato giudiziario; sarebbe pertanto ingenuo e semplicistico ignorare la svolta avvenuta, è bene pertanto che in futuro... si proceda ad un coordinamento organico e ad un riordino globale del sistema proprio alla luce dei Motu Propio, rivedendo discrasie e contrasti» (M. DEL Pozzo, L'impatto della riforma sul diritto processuale vigente, cit., 5.1, 14).

39 Parte de la doctrina ha sido crítica con esta indicación [vid., por ejemplo, G. BONI, La recente riforma del processo di nullità matrimoniale. Problemi, criticità, dubbi. dubbi (parte terza: \$SS 5-7), cit., $\$ 5.4,21-34$; C. Dounot, La reforme de la procedure des nullites de mariage au regard des principes juridiques, en C. DOUNOT - F. DussaubaT (eds.), La réforme des nullités de mariage, une étude critique, Artège Lethielleux, Perpignan 2016, 59-60], arguyendo que el empleo de la expresión «fracaso», eludida por el CIC 83 y por la Dignitas Connubii, podría llevar al equívoco de equiparar fracaso del matrimonio y nulidad del mismo, algo que el propio Juan Pablo II había denunciado en el discurso a la Rota romana de 1987: «el fracaso de la unión conyugal, por otra parte, no es en sí mismo jamás una prueba para demostrar la incapacidad de los contrayentes...»; también en su discurso a la Rota romana de 2004: «¿Qué decir, entonces, de la tesis según la cual el fracaso mismo de la vida conyugal debería hacer presumir la invalidez del matrimonio? Por desgracia, la fuerza de este planteamiento erróneo es a veces tan grande, que se transforma en un prejuicio generalizado, el cual lleva a buscar las pruebas de nulidad como meras justificaciones formales de un pronunciamiento que, en realidad, se apoya en el hecho empírico del fracaso matrimonial. Este formalismo injusto de quienes se oponen al favor matrimonii tradicional puede llegar a olvidar que, según la experiencia humana marcada por el pecado, un matrimonio válido puede fracasar a causa del uso equivocado de la libertad de los mismos cónyuges» (JUAN PABLO II, Discursos a la la Rota romana de 5 de febrero de 1987 y de 21 de enero de 2004, en www.iuscanonicum. 
lla- pone el acento en la necesidad de que el juez emplee $\ll$ los medios pastorales para inducir a los cónyuges, si es posible, a convalidar su matrimonio y a restablecer la convivencia», aunque sigue siendo oportuno -y por tanto mantienen su vigencia-, que el juez haga las recomendaciones a que se refieren los $\$ \$ 2$ y 3 de ese mismo art. $65^{40}$.

- El can. 1676 introduce importantes novedades relativas a la fase de introducción de la causa, estableciéndose un régimen jurídico distinto del que fijan los cann. $1505 \$ 1,1507$ y 1513 para el resto de procesos; en efecto, de acuerdo con los $\$ \$ 1$ y 2 , la admisión de la demanda, la citación y la fijación del dubium le corresponde al vicario judicial ${ }^{41}$, lo comporta la derogación de las siguientes normas de la Dignitas Connubii relativas a esta fase inicial: $1^{\circ} \mathrm{El}$ art. 118 , que obligaba al vicario judicial a constituir el tribunal una vez presentado el escrito de demanda, y a notificar su constitución; $2^{\circ} \mathrm{El}$ art. 119 y el art. $46 \$ 2,7^{\circ}$, que

org). En realidad, lo que se presume es que, una vez se ha tomado la iniciativa de acudir al tribunal, es ya del todo imposible -o al menos ciertamente improbable- recomponer la convivencia. Así se indica textualmente en el Subsidio de la Rota Romana: «È necessario esperire il tentativo di riconciliazione? L'esperienza dice che, quando si arriva alla causa di nullità, è già del tutto impossibile ricomporre la convivenza. Pertanto basterà che il giudice, prima di accettare la causa, abbia la certezza che il matrimonio sia irreparabilmente fallito, e sia impossibile ristabilire la convivenza coniugale» (Tribunale Apostolico della Rota Romana, Sussidio applicativo del motu proprio Mitis iudex Dominus Iesus, Città del Vaticano 2016, 23). En mi opinión, y más allá de cuestiones terminológicas y de matices, no creo que se pueda afirmar con un mínimo fundamento que el legislador ha equiparado el fracaso a la nulidad.

${ }^{40}$ Que los cónyuges colaboren sinceramente en el descubrimiento de la verdad a lo largo del proceso y que depongan toda aversión recíproca y mantengan una actitud afable, humana y caritativa.

${ }^{41} \mathrm{El}$ anterior canon habla de juez ( $\ll \mathrm{El}$ juez, antes de aceptar una causa...»), y también el art. 10 de la Ratio Procedendi («el juez puede aceptar la demanda oral...»). En mi opinión, la norma del can. 1676 casa mal con el criterio de celeridad, pues hará que los eventuales recursos de inadmisión de la demanda, y también el recurso del dubium y los eventuales recursos que puedan suscitar con ocasión de la determinación del proceso a seguir (ordinario o brevior ante el obispo) tengan que ir al tribunal superior, además de obligar al vicario judicial a admitir todas las demandas y realizar todos los trámites de la fase inicial (hasta el dubium y la posterior determinación del Turno, ello si no se sigue el proceso brevior ante el obispo); por ello, hemos propuesto una praxis que, siendo respetuosa con el can. $1676 \$ 1$, introduzca criterios de «obrar jurídico y procesal», y también criterios más respetuosos con el pretendido tratamiento judicial de los procesos de nulidad [vid. C. M. Morán Bustos, El proceso «brevior» ante el obispo, en M. E. OlMos Ortega (ed.), Procesos de nulidad matrimonial..., cit., 155-157]: admitir la demanda y fijar el dubium son actos procesalmente hablando decisivos, y, en mi opinión, parece de lógica procesal que los mismos sean dados por quien después va a formar parte del Turno, algo que no tiene porqué ser así si siempre le corresponde al vicario judicial (salvo que se le obligue a formar parte de todos los Turnos); el criterio del can. 1676 plantea problemas desde el punto de vista de la lógica jurídico-procesal, y también puede plantear serios problemas desde el punto de vista de la celeridad procesal. 
reservaba la admisión-rechazo de la demanda al presidente del Turno $(\$ 1$, en línea con el can. $1505 \$ 1$ ), para lo cual había de oír antes al defensor del vínculo $(\$ 2) ; 3^{\circ} \mathrm{El}$ art. 120 relativo a la investigación previa que el presidente podía establecer en determinados supuestos ${ }^{42} ; 4^{\circ} \mathrm{El}$ art. $46 \$ 2,1^{\circ}-9$-y también el art. $140,1^{\circ}$ y $2^{\circ}-$, que recogía diversos trámites procesales de la fase introductoria encomendados y dirigidos por el presidente ${ }^{43}$ (alguno de ellos encomendados, en su caso, también al ponente por el art. $47 \$ 2) ; 5^{\circ} \mathrm{El}$ art. $126 \$ 1-\mathrm{y}$ el art. $46 \$ 2,7^{\circ}-9^{\circ}-$ que encomendaba la citación al demandado al presidente, así como los arts. 127 y $46 \$ 2,7^{\circ}-9^{\circ}$ respecto de diversas actuaciones relacionadas con la citación también por parte del presidente; $6^{\circ} \mathrm{El}$ art. $135 \$ 1$-y el art. $46 \$ 2,10^{\circ}$ - que encomendaba la fijación del dubium al presidente (o en su caso al ponente, art. $47 \$ 2$ ); $7^{\circ} \mathrm{El}$ art. $138 \$ 1-\mathrm{y}$ el art. $46 \$ 2$, $12^{\circ}$ - que obligaba al presidente o al ponente a declarar la ausencia del demandado ${ }^{44}$.

- El can. $1678 \$ 4$ se refiere al supuesto de suspensión del proceso de nulidad una vez que surgen dudas sobre la inconsumación del matrimonio, exigiendo para ello únicamente «oír a las partes», no el consenso de las mismas, lo que supone la derogación del art. $153 \$ 1$ Dignitas Connubii.

42 «Tal investigación previa [DC $120 \$ 2$ ], empero, no puede ser confundida con la prejudicial o pastoral del MP: aquella primera es ordenada de oficio por un órgano revestido de potestad judicial y da por supuesta la introducción de la demanda; esta segunda, será ordenada por un órgano revestido de potestad administrativa a instancia de parte y tiene por finalidad, concluir o no, con un hipotético escrito de demanda» [F. J. REgORDán, La investigación prejudicial del Motu Proprio «Mitis Iudex Dominus Iesus», en UnIVERsidad Católica de VAlencia «SAN Vicente MártiR», Facultad de Derecho CanónICo (ed.), XIII Conversaciones Canónicas Valentinas. «Mitis Iudex Dominus Iesus»: algunas cuestiones en torno a la reforma de los procesos de la nulidad matrimonial, Valencia, 8-10 de febrero de 2016, Anuario de Derecho Canónico 5 (Octubre 2016) 45].

43 Designación del ponente y del auditor (art. $46 \$ 2,1^{\circ}$ y $2^{\circ}$ ), resolver la excepción contra los ministros del tribunal (art. $46 \$ 2,3^{\circ}$ ), ejercer la disciplina sobre los que actúan en juicio (art. 46 $\$ 2,4^{\circ}$ ), admitir o designar curador (art. $46 \$ 2,5^{\circ}$ ), proveer sobre procurador y/o el abogado (art. $46 \$ 2,6^{\circ}$ ), la ya referida admisión-rechazo de la demanda y citación del demandado (art. 46 $\$ 2,7^{\circ}-8^{\circ}$ y $13^{\circ}$ ), la decisión eventual de no dar traslado de la demanda al demandado (art. $46 \$ 2$, $9^{\circ}$ ); en caso de que al actor no comparezca a la sesión para fijar el dubium (art. 140, $1^{\circ}-2^{\circ}$ ), la nueva citación del mismo y, en caso de continuar ausente, la declaración de la causa como desierta.

44 Salvo que se trate de un supuesto de ausencia sobrevenida, la declaración de ausencia del demandado procederá realizarse tras la citación de éste, de modo que será el vicario judicial quien habrá de dar el decreto de declaración de ausencia que el can. $1592 \$ 2$ establece en términos de obligatoriedad (no es potestativo para el vicario judicial). 
- La supresión de la duplex conformis que establece el can. 1679 es una de las grandes novedades del M. P. Mitis Iudex y comporta la derogación de todo el sistema procesal que estaba detrás del mecanismo del doble pronunciamiento conforme; en concreto, se ha de considerar derogado el art. 264 -y parcialmente también el art. $301 \$ 1-$ y también el art. 265, al menos la aplicación automática del mismo (ex antiguo can. $1682 \$ 2$ y $\$ 1$ ), aunque este mecanismo sí que es útil a los efectos de completar todo el procedimiento de apelación «tan peculiar» que se ha establecido.

- El can. 1681 regula la nova causa propositio en caso de sentencia «ejecutiva» ${ }^{45}$, estableciéndose como tribunal competente para conocer de la misma el de tercera instancia; este canon se completa con el n. II del Rescriptum ex audientia de 7-XII-2015, según el cual, una vez que las partes han accedido a nuevo matrimonio, no cabe presentar el recurso extraordinario de revisión ${ }^{46}$; ambas disposiciones suponen la derogación del criterio que establece el art. $290 \$ 1$.

En resumen, se han de considerar derogados todos aquellos artículos de la Dignitas Connubii que sean contrarios al M. P. Mitis Iudex, o aquellos cuyo contenido ha sido modificado e innovado. Al margen de ello, «no veo razón alguna para entender que todas las demás soluciones prácticas o medios de coordinación que se reflejan en los demás artículos de la Instrucción no deba considerarse que se mantienen tras la vigencia de M. P. Mitis Iudex Dignitas Connubii sigue siendo en la mayoría de sus pasajes un documento práctico tan válido para aclarar dudas y solucionar problemas planteados... en la medida en que no haya contradicción con las nuevas normas..., puede y debe seguir aplicándose Dignitas Connubii ${ }^{47}$.

${ }^{45}$ La terminología es muy impropia, pues las sentencias de nulidad de matrimonio no se ejecutan, lo impide su propia naturaleza declarativa, ni generan para las partes obligaciones que requieran de una ejecución a tenor de los cann. 1650-1655.

46 Ello «a menos que conste claramente la injusticia de la decisión» [FRANCISCO, Rescripto del Santo Padre Francisco sobre el cumplimiento y la observacia de la nueva ley del proceso matrimonial, 7 de diciembre de 2015, en vatican.va, 11-XII-2015, n. II.3, y en L'Osservatore Romano 155 (2015), 12XII-2015, p. 8, n. II.3]; en este punto, el Rescripto del Papa Francisco actualiza lo establecido en el n. II del Rescripto de 11 de febrero de 2013 del Papa Benedicto XVI [SEgretaria Di Stato, Rescriptum ex audientia SS.mi 11 febraio 2013, N. 208.966; vid. C. M. Morán Bustos, Las Facultades Especiales de la Rota Romana: claves interpretativas y cuestiones que suscitan, en J. BosCH (ed.), Actas de las XXXIV jornadas de la actualidad canónica organizadas por la Asociación Española de Canonistas en Madrid, 23-25 de abril de 2014, Madrid 2015, 391-462].

47 R. Rodríguez CHACón, Antecedentes, estructura y valor jurídico en el sistema normativo canónico..., cit., 56-57. 
El sentido común, la prudencia y el realismo jurídico, y la interpretación y aplicación del M. P. Mitis Iudex desde la lógica de la continuidad a la que nos hemos referido, nos impulsa por tanto a usar el articulado de la Dignitas Connubii con carácter supletorio y a modo de desarrollo de la disciplina codicial: «si no se puede renunciar a insertar la reforma en el horizonte codicial, no se puede ignorar o pasar por encima de su principal expresión operativa» ${ }^{48}$.

Dicho esto, también creo que es oportuno, más allá de analizar qué artículos concretos se han de considerar derogados, hacer una interpretaciónaplicación de los artículos de la Dignitas Connubii en vigor -por no ser contrarios a la reforma- desde la óptica de la intentio y de los criterios perseguidos por la reforma, fundamentalmente de los siguientes: la búsqueda de la celeridad ${ }^{49}$, simplificación de los procesos, gratuidad, compromiso del obispo diocesano en el desempeño de la función judicial ${ }^{50}$, principio de proximidad-accesibilidadcercanía juez-fiel, el tribunal diocesano como modelo organización judicial... ${ }^{51}$

Es posible que en un futuro más o menos inmediato se piense en la oportunidad de una «nueva Instrucción»-igual que ocurrió con la Provida Mater Eclesia y con la propia Dignitas Connubii- que tenga, no sólo un carácter supletorio, de desarrollo y de concreción de silencios y lagunas normativas, sino un carácter normativo más específico, que venga a ser una especie de «nueva reformulación» que tome en consideración la peculiaridad de instituciones procesales novedosas, principalmente de la fase de investigación prejudicial o pastoral, y del proceso brevior ante el obispo -extrañas a la Dignitas Connubii-, y también otra serie de instituciones procesales que han sido sustancialmente modificadas; entre éstas, me refiero, por ejemplo, a los títulos de competencia, la fase introductoria, la apelación y el recurso extraordinario de revisión ${ }^{52}$, así como de todo lo relativo a la «ejecución» de las sentencias. Antes de plantearse una nueva Instrucción, sin embargo, creo que sería oportuno darnos un tiempo de adaptación y asimilación, de consolidación y de sedimentación de la reforma, un tiempo de «rodaje» ${ }^{53}$, no sólo con el fin de evitar precipitaciones, sino para tener una experiencia de la que extraer datos útiles para un mejor proveer normativo.

${ }^{48}$ M. DEL Pozzo, L'impatto della riforma sul diritto processuale vigente..., cit., $\$$ 5.2, 15-16.

49 Cfr. C. M. Morán Bustos, Retos de la reforma procesal de la nulidad del matrimonio..., cit., 55-56.

${ }^{50}$ Cfr. C. M. Morán Bustos, El proceso «brevior» ante el obispo..., cit., 131-135.

${ }^{51}$ Cfr. C. M. Morán Bustos, Criteri organizzativi dei tribunal e criteri d'azione degli operatori giuridici dopo la promulgazione del M. P. Mitis Iudex, cit., 115-133.

${ }_{53}$ Cfr. M. DEL Pozzo, Limpatto della riforma sul diritto processuale vigente..., cit., $\$ 5.2,16$.

${ }^{53}$ Cfr. J. LlobELL, Alcune questioni comuni ai tre processi per la dichiarazione..., cit., 18; R. RodRíGUEZ CHACón, Antecedentes, estructura y valor jurídico en el sistema normativo canónico..., cit., 57. 


\section{El valor hermenéutico de la Dignitas ConNubit más allá DE SU VIGENCIA DESDE EL PUNTO DE VISTA NORMATIVO}

Como se ha dicho, la Dignitas Connubii no es una Instrucción al uso, no es una norma que se limite a aclarar-desarrollar los preceptos codiciales sobre los procesos de nulidad, sino que es una norma que comportó una verdadera reordenación-unificación de toda la normativa que había de aplicarse a estas causas, una norma que recogió y «positivizó» aspectos importantes del Magisterio Pontificio -sobre todo de los discursos a la Rota romana-, así como toda una serie de criterios jurisprudenciales y de la praxis de la curia romana (fundamentalmente de la Rota romana, del STSA y respuestas del PCITL). Como se indica en el Proemio, la Dignitas Connubii tenía una finalidad y un carácter marcadamente pedagógico, de modo que «los jueces y ministros de los tribunales fueran como llevados de la mano (veluti manuducantur) en la resolución de asuntos de gran importancia... evitando las dificultades que pueden presentarse en el desarrollo del juicio o a causa del modo como se han organizado en el código las normas sobre este proceso» ${ }^{54}$.

El resultado fue un «cuerpo normativo», en mi opinión, técnicamente muy bueno -por supuesto perfectible, como todos, con puntuales aspectos matizables...-, que ha servido de ayuda para los operadores jurídicos -a los que ciertamente ha «llevado de la mano»- y en el que se incorporan algunos criterios y prescripciones concretas cuyo valor va más allá de su vigencia normativa. Aunque es evidente que algunos de los artículos hoy han perdido vigencia -hemos aludido a diversos artículos que se han de considerar derogados-, también lo es que en la Dignitas Connubii hay algunas normas referidas a determinadas instituciones procesales que son todo un precedente histórico que ha de ser atendido, normas que forman parte ya de lo que podríamos llamar un «patrimonio-depósito jurídico-procesal»; normas, no sólo que se pueden aplicar hoy, sino normas cuyo contenido -más allá de los matices y actualizaciones con las que se tendrán que revestir- será necesario aplicar en cualquier momento, pues son una conquista y un avance desde el punto de vista de la ciencia procesal, y también una ayuda desde el punto de vista de la praxis forense. Desde luego, hay normas en la Dignitas Connubii que tienen claramente un valor hermenéutico de la reforma procesal que se ha realizado, un valor

${ }^{54}$ Cfr. G. P. MonTINI, Listruzione «Dignitas Connubii» sui processi di nullità matrimoniale..., cit., 351. 
que creo va más allá de la impostación didascálica y prontuarística que tiene el Subsidio aplicativo de la Rota romana ${ }^{55}$.

Sin ánimo de exhaustividad alguna, me permito apuntar alguna norma de éstas cuyo valor objetivo y de contenido va más allá de su vigencia normativa, y también alguna que claramente tiene valor hermenéutico de la reforma del M. P. Mitis Iudex:

1. Los criterios generales que los artículos preliminares establecen respecto del ámbito-objeto del ejercicio de la potestad judicial en la Iglesia, así como respecto de la aplicabilidad del derecho procesal canónico y la determinación del derecho matrimonial sustantivo aplicable en las causas de nulidad del matrimonio; alguno de ellos aparecen en el nuevo can. 1671, pero creo que es interesante tener en cuenta algunos de los restantes criterios que en esos artículos se fijan, pues ayudararán a solucionar muchos problemas que se plantean en nuestros tribunales: $1^{\circ}$ Las causas matrimoniales de los bautizados - basta que sea bautizada una de las partes, sea católica o no- corresponden al juez eclesiástico por derecho propio (art. $3 \$ 1 \mathrm{DC}$, can. $1671 \$ 1$ ); $2^{\circ}$ La Iglesia también ejerce su jurisdicción sobre el matrimonio entre acatólicos, bautizados o no, para comprobar el estado de libertad al menos de una de las partes ante la Iglesia católica (art. $3 \$ 2$ ); $3^{\circ}$ Respecto de los efectos meramente civiles del matrimonio, es competente el juez civil (art. $3 \$ 3$, can. $1671 \$ 2$ ); $4^{\circ}$ Con independencia del carácter canónico o no del matrimonio cuya validez se discute, el derecho procesal a aplicar por el tribunal eclesiástico que conoce de la validez-nulidad del matrimonio es el derecho procesal canónico (art. $4 \$ 2,1^{\circ}$ ); $5^{\circ}$ Por lo que se refiere a la normativa sustantiva, el punto de partida es que la validez del matrimonio depende directamente de la ley a la que estaba sometido ese matrimonio: si al menos uno de los cónyuges es católico, se rige por el derecho divino y por

55 «Il Sussidio applicativo non è chiaramente paragonabile allo scopo e allo spirito della Dignitas Connubii. La sua rapidissima preparazione e l'impostazione stremamente didascálica e prontuaristica (si pensi ai quadri sintetici e agli specimina) lo rende un supporto di avvio e di guida all'esecuzione della reforma più che uno strumento di analisi e specificazione operativa e giurisprudenziale delle disposizioni. Manca ancora d'altronde l'esperienza e la prassi che possa assicurare un prospetto affidabile in tale linea. Limpronta del Sussidio applicativo e in generale l'ideale di una legge "leggera e aperta" per la verità sembrano un po' prendere le distanze dallo stile e dall'approccio delle precedenti istruzioni» (M. DEL POzzo, L'impatto della riforma sul diritto processuale vigente..., cit., $\$ 5.2,16$ ). 
el derecho canónico; en los casos de matrimonios mixtos (entre católico y bautizado no católico) -respecto de los matrimonios dispares no se indica nada-, además del derecho divino y del derecho canónico, se rigen también por el derecho matrimonial de la comunidad eclesial del acatólico, o en su defecto, por el derecho que se use en dicha comunidad eclesial (art. $2 \$ 2$ ); si son dos bautizados acatólicos, el derecho que ha de aplicar el juez eclesiástico es aquel al que estaban obligados al contraer (art. 4 $\$ 1$ ); este mismo criterio se aplica en el caso de dos no bautizados, ello salvando siempre el derecho divino (art. $4 \$ 2$ ); si son dos católicos de rito oriental, sigue siendo válido $-\mathrm{y}$ valioso- el criterio del art. 16 de que el tribunal latino pueda juzgar, bien ipso iure -si no tienen jerarca local de cualquier otra iglesia sui iuis donde la cura pastoral de los fieles se haya encomendado al ordinario latino-, bien por prórroga de competencia de la Signatura Apostólica (art. $16 \$ 11^{\circ}$ y $2^{\circ}$ ), para lo cual el tribunal latino aplicará sus propias normas procesales y las normas sustantivas de la Iglesia sui iuris; $6^{\circ} \mathrm{El}$ matrimonio civil o contraído en forma no canónica por los obligados a la forma canónica (can. 1117) sólo requerirá de una comprobación administrativa del estado de libertad (art. $5 \$ 3$ ).

2. Por lo que respecta a los artículos relativos a la competencia (tit. II), en la Dignitas Connubii hay algunos criterios muy válidos que se deberían seguir tomando en consideración; por ejemplo los siguientes: $1^{\circ}$ La delimitación de la incompetencia absoluta por razón de la materia una vez creado un tribunal interdiocesano, se debería seguir aplicando el criterio del art. $9 \$ 2$ b, por razón del grado, y sobre todo, la incompetencia absoluta derivada del principio ne bis in eadem, que se concreta en la prohibición que establece el art. $9 \$ 2$ de que una misma causa sea juzgada dos veces en una misma instancia, aunque sea por un tribunal distinto (art. $289 \$ 2$ ), así como la prohibición en virtud del mismo principio de que el tribunal revoque una sentencia dictada por él (art. 259); con la configuración que se ha hecho de los títulos de competencia y con la propia supresión de la duplex conformis deberían, así como con la ausencia de mecanismos de control y de comunicación entre tribunales, se hace más necesario que nunca tener presente estas concreciones, pues fácilmente se verá violado este principio; $2^{\circ} \mathrm{La}$ aplicación del criterio de conexión de las causas del art. 15, no como posibilidad, sino como obligación, ello como exigencias del principio de economía procesal y también por razones de celeridad; $3^{\circ}$ La especificación del modo de actuar cuan- 
do, tras haberse decretado la renuncia o la caducidad, la parte tiene intención de continuar con la tramitación de la causa (arts. 19 y 152).

3. Hay también en la Dignitas Connubii una serie de recomendaciones que son verdaderos principios rectores de lo que ha de ser un auténtico obrar deontológico de los diversos operadores jurídicos, un obrar según criterios de «deber ser», cuyo valor sobrepasa los límites de su vigencia; así ocurre, por ejemplo, con las siguientes normas: $1^{\circ} \mathrm{La}$ recomendación que se hace a los obispos para que nombren ministros de justicia idóneos (art. 33, $1^{\circ}$ ), y a éstos para que desempeñen su función de modo celoso y conforme a derecho (art. 33, $2^{\circ}$ ), correcta y fialmente, con conocimiento cada vez mayor del derecho matrimonial y procesal y de la jurisprudencia (art. 35); $2^{\circ}$ La obligación -en este caso es más que una recomendación- del tribunal de proveer que la parte pueda ser asistida por patrón (art. $101 \$ 1$ ) y la obligación del abogado de tutelar los derechos de las partes (art. 104) y de aceptar el patrocionio gratuito (arts. $112 \$ 2$ y 307); $3^{\circ}$ Algunas recomendaciones relacionadas con la búsqueda de la verdad -por ejemplo, que se atienda al criterio de licitud y utilidad a la hora de aceptar las pruebas (art. $157 \$ 1$ ), que se deje constancia de la fuente de conocimiento de los hechos que se declaran (art. 202)...-, con la diligencia y celeridad -por ejemplo, que se evite un número excesivo de testigos y se inadmitan pruebas dilatorias (art. $157 \$ 3$ )...-, y con la discreciónreserva a la hora de manejar los datos e informaciones que se suscitan en un proceso tan delicado como es el de nulidad del matrimonio (por ejemplo, el art. $235 \$ 2$ ); $4^{\circ}$ La recomendación del art. 205 para que se nombren peritos a personas que destacan por su capacitación, ciencia y experiencia profesional, y también por su religiosidad y honestidad, así como por su respeto a los criterios de la antropología cristiana (arts. 205)...

4. También se habrá de seguir aplicando el régimen de incompatibilidades que establece la Dignitas Connubii (arts. 36 y 66), el cual, en la medida en que responde a una mejor protección y garantía de la independencia, imparcialidad y libertad -evitando todo tipo de suspicacias al pueblo fiel en general y a las partes en particular-, seguirá teniendo valor más allá de ulteriores disposiciones; los elementos esenciales de este régimen de incompatibilidad son los siguientes: $1^{\circ} \mathrm{El}$ vicario judicial, los jueces, defensores del vínculo y promotores de justicia no pueden ejercer establemente dichos oficios en dos tribunales conexos por razón de apelación (art. $36 \$ 1$ ), ni tampoco pueden desempeñar establemente dos ofi- 
cios simultaneamente en el mismo tribunal ${ }^{56}$, bien se trate de la misma causa o de causa distinta; $2^{\circ}$ Los ministros del tribunal no pueden actuar como abogados o procuradores -ni personalmente ni por medio de persona interpuesta- en dicho tribunal o en otro conexo con aquél por razón de apelación (art. $36 \$ 3)^{57} ; 3^{\circ}$ Quien ha intervenido como defensor del vínculo, promotor de justicia, procurador, abogado, testigo o perito, no puede definir válidamente la causa como juez -ni puede ser asesor- en la misma causa o en otra instancia (art. $66 \$ 2$ ).

5. La Dignitas Connubii continuará siendo criterio hermenéutico a la hora de analizar el contenido de la demanda (art. 116) -o los motivos de inadmisión de la misma (arts. 121-122)-, a la hora de precisar el régimen de notificaciones que hay que hacer a las partes en función de las diversas posiciones procesales que adopten (art. 134); igualmente, especialmente útil son muchas disposiciones que traducen al ámbito específico de los procesos de nulidad cuestiones generales relacionadas con la proposición y práctica de las pruebas y con el examen judicial -arts. 155-161 y 162-176-, y también muchas normas sobre cada uno de los medios de prueba (declaración-confesión de las partes, documental, testifical y pericial); a este respecto, la mayor parte de las precisiones que se establecen sobre la prueba pericial seguirán teniendo un valor incuestionable, pues concretan las directrices fijadas por la jurisprudencia y por los Romanos Pontífices (fundamentalmente en sus discursos a la Rota romana): pienso, por ejemplo, en el principio de necesidad de pericia en los supuestos

${ }^{56}$ En este caso, con la excepción de defensor del vínculo y promotor de justicia, aunque no podrán ser en la misma causa (can. $1436 \$ 1$ ).

57 Esta prohibición del art. $36 \$ 3$ cubre una laguna del CIC 83 y, en la medidad que es de sentido común procesal, seguirá teniendo sentido más allá de la vigencia de la Dignitas Connubii. En efecto, el can. 1447 prohíbe a los vicarios judiciales, jueces, defensor del vínculo y promotor de justicia ser juez o asesor «en otra instancia», pero no dice nada de la misma instancia, y podría ocurrir, sobre todo con ocasión de nombramientos advenedizos, que uno fuera defensor del vínculo y después juez; de hecho, así se ha producido en algún supuesto; es verdad que la doctrina mayoritaria interpretaba que no pudiendo actuar en una instancia superior, menos podía hacerlo en la misma instancia. El art. $36 \$ 2$ prohíbe desempeñar dos oficios en el mismo tribunal, independientemente de la instancia que sea, pero dice «simultáneamente» («simul»); según eso, uno que era defensor del vínculo, por ejemplo, podrá ser nombrado en ese mismo tribunal juez (de hecho, el art. $43 \$ 4$ recomienda este tipo de situaciones), ya que en ese caso no desempeñaría ambos oficios «simultáneamente», pero ¿podrá serlo en la misma causa? Este supuesto no está expresamente recogido ni en el can. 1447, ni en el art. $36 \$ 1$, pero sí en el art. $66 \$ 2$ [cfr. C. M. Morán Bustos, Comentario al título II: los tribunales (arts. 22-64 DC), en C. M. Morán Bustos - C. PeÑa GarCía, Nulidad de matrimonio y proceso canónico, Madrid 2007, 108]. 
de incapacidad para consentir que establece el art. 203, o en todo lo relativo al mecanismo de designación del perito (arts. 204, 207) y de realización de la pericia (art. 210), y sobre todo, en todo lo relativo a la delimitación del objeto de la pericia en los supuestos de impotencia (art. 208) y en cada uno de los supuestos del can. 1095 que hace el extraordinario art. 209. Por lo que respecta a la sentencia, seguirá siendo de aplicación, por ejemplo, cuanto se refiere al veto (art. 251), o lo relativo al cómputo de los plazos para interponer (art. 281) y proseguir la apelación -suprimida la duplex conformis y el mecanismo de envío de oficio de los autos al tribunal superior (can. $1682 \$ 1$ ), creo que sería oportuno que hubiera una precisión ulterior sobre los momentos a quo y ad quem de interponer y proseguir la apelación, pues está en juego el ius apellandi-, y también todo lo relativo a la «ejecución» de la sentencia declarativa de la nulidad del matrimonio (arts. 300-301).

6. Por último, mientras no se haga una nueva regulación de todo el mecanismo relativo a las causas incidentales, se hace imprescindible echar mano de cuanto establecen los arts. 217-228, pues precisan las disposiciones de los cann. 1587-1591, concretándolas al ámbito específico de los procesos de nulidad. Igualmente, en ausencia de fuentes normativas para los procedimientos disciplinares-sancionadores ligados a actuaciones en el foro canónico, creo que se podrá usar como fuente a tal efecto los arts. $75,87,110,111 \ldots$

\section{A MODO DE CONCLUSIÓN}

Más allá de la configuración concreta que se haga de las diversas instituciones procesales canónicas en cada momento histórico-eclesial, es importante situarse en una perspectiva más general, en la perspectiva de la ratio y de la historia del proceso de nulidad. Pues bien, mirada la reforma en su conjunto, se advierte que han resultado inalterados los elementos esenciales que configuran el proceso de nulidad, por ello hemos hablado de que la reforma del Papa Francisco sigue la lógica de la continuidad procesal. A nivel legislativo, por tanto, no creo que se pueda hablar de una ruptura, ni con la historia, ni con la tradición, ni con la ratio última del proceso de nulidad.

Es evidente que las innovaciones y modificaciones introducidas en algunas instituciones procesales han sido relevantes, respondiendo todas ellas a la voluntad del Papa de procurar una verdadera «conversión de las estructuras», 
también de las estructuras jurídicas. En mi opinión, es éste el espíritu con el que hemos de acoger la reforma procesal del Papa Francisco, que debe ser aplicada por parte de los operadores jurídicos también desde la lógica de la continuidad «sustantiva»; esto es, buscando la verdad del vínculo conyugal y protegiendo y respetando su indisolubilidad, pues aquí está la ratio última del M. P. Mitis Iudex.

Esta lógica de la «continuidad procesal legislativa»y de la «continuidad sustantivo-material forense» es la que nos impulsa a echar mano de la Dignitas Connubii con carácter supletorio y de desarrollo de la disciplina codicial a la que -con el presupuesto del art. 6 de la Ratio Procedendi-reenvía el can. 1691 $\$ 3$. Más aún: por encima de la vigencia normativa, la Dignitas Connubii seguirá teniendo un valor hermenéutico indubitable. 


\section{Bibliografía}

BONI, G., La recente riforma del processo di nullità matrimoniale. Problemi, criticità, dubbi. dubbi [parte prima: SSS 1-3], Stato, Chiese e pluralismo confessionale. Rivista telemática 9 (2016) 1-78 [http://www.statoechiese.it/7 marzo 2016].

Daneels, F., Una introducción general a la Instrucción Dignitas Connubii, en R. Rodríguez Ocaña - J. SEdano (eds.), Procesos de nulidad matrimonial. La Instrucción «Dignitas Connubii», Pamplona 2006, 21-44.

Daniel, W. L., An Analysis of Pope Francis' 2015 Reform of the General Legislation Governing Causes of Nullity of Marriage, The Jurist 75 (2015) 429-466.

De Bertolis, O., Papa Francesco riforma il processo canonico matrimoniale, La civiltà cattolica 166 (2015/IV) 59-66.

Del Pozzo, M., Dal «tribunale limitrofo» al «tribunale sussidiario»: una proposta di migliore sistematizazione concettuale della nozione, en J. KowAL - J. LLOBELL (eds.), Iustitiam et iudicium: studi di diritto matrimoniale e processuale canonico in onore di Antoni Stankiewicz, Città del Vaticano 2010, 1627-1644; IDEM, L'organizzazione ecclesiastica alla luce del M. P. Mitis Iudex, en www.statoechiese.it 36/201, noviembre 2015, 1-33; M. DEL Pozzo, L'impatto della riforma sul diritto processuale vigente, Associazione Canonistica Italiana, Udine, settembre 2016, en vías de publicación.

DounOt, C., La reforme de la procedure des nullites de mariage au regard des principes juridiques, en C. Dounot - F. Dussaubat (eds.), La réforme des nullités de mariage, une étude critique, Artège Lethielleux, Perpignan 2016, 61-68.

GONZÁlez AYesta, J., Valor jurídico de la Instrucción Dignitas Connubii en el marco del sistema normativo canónico de fuentes del derecho, en R. RODRÍGUEZ CHACÓN - L. RUANo EsPina (eds.), Los procesos de nulidad de matrimonio canónico, Madrid 2006, 25-50.

Llobell, J., El valor jurídico de la instr. «Dignitas Connubii», su recepción eclesial, el objeto y la conformidad de la sentencia, y la certeza moral, en R. RODRÍGUEZ OcaÑa - J. SEDAno (eds.), Procesos de nulidad matrimonial. La Instrucción «Dignitas Connubii», Pamplona 2006, 235-301; IDEM, El ejercicio personal de la potestad judicial del obispo diocesano. Algunas consideraciones preliminares al M. P. «Mitis Iudex» y al M. P. «Mitis et Misericors», Revista General de Derecho Canónico y Eclesiástico del Estado 41 (2016) 1-21, en www.iustel. com; IDEM, Alcune questioni comuni ai tre processi per la dichiarazione di nullità del matrimonio previsti dal M. P. «Mitis Iudex», Ius Ecclesiae 28 (2016) 1338; IDEM, Quelques questions communes aux trois procès pour la déclaration de 
nullité du mariage prévus par le motu proprio «Mitis Iudex», en E. CAPARROS - L. NAvarRo - Th. Sol (eds.), La réforme opérée par le M. P. «Mitis Iudex». Commentaires et documentation. Actes d'un colloque organisé par LUMSA Università et Consociato Internationalis Studio Iuris Canonici Promovendo, Rome, 30 novembre 2015, Montréal-Paris 2016, 31-61.

MontinI, G. P., L'istruzione «Dignitas Connubii» sui processi di nullità matrimoniale. Una introduzione, Quaderni di Diritto Ecclesiale 18 (2005) 342-363; IDEM, L'istruzione «Dignitas Connubii» nella gerarchia delle fonti, Periodica de re Canonica 94 (2005) 417-476.

Morán Bustos, C. M., El proceso «brevior» ante el obispo, en M. E. Olmos Ortega (ed.), Procesos de nulidad matrimonial. Tras la reforma del Papa Francisco, Madrid 2016, 125-176; IDEM, Retos de la reforma procesal de la nulidad del matrimonio, Ius Canonicum 56 (2016) 9-40; IDEM, Criteri organizzativi dei tribunal e criteri d'azione degli operatori giuridici dopo la promulgazione del M. P. Mitis Iudex, en H. FranCESCHI - M. Á. OrTIZ (eds.), Ius et matrimonium II. Temi processuali e sostanziali alla luce del Motu Proprio Mitis Iudex Dominus Iesus. Subsidia Canonica 21, Roma 2017, 97-178.

Morán Bustos, C. M. - PeÑa García, C., Nulidad de matrimonio y proceso canónico, Madrid 2007.

OTAduY, J., El principio de jerarquía normativa y la Instrucción Dignitas Connubii, Ius Canonicum 46 (2006) 59-97.

—, El principio de jerarquía normativa y la Instrucción «Dignitas Connubii», en R. Rodríguez Ocaña - J. Sedano (eds.), Procesos de nulidad matrimonial. La Instrucción «Dignitas Connubii», Pamplona 2006, 45-80.

Regordán, F. J., La investigación prejudicial del Motu Proprio «Mitis Iudex Dominus Iesus», en Universidad Católica de VAlenCia «SAN Vicente MártiR», Facultad de Derecho Canónico (ed.), XIII Conversaciones Canónicas Valentinas. «Mitis Iudex Dominus Iesus»: algunas cuestiones en torno a la reforma de los procesos de la nulidad matrimonial, Valencia, 8-10 de febrero de 2016, Anuario de Derecho Canónico 5 (Octubre 2016) 39-52.

Rodríguez Chacón, R., Antecedentes, estructura y valor jurídico en el sistema normativo canónico de los dos Motu Propio de 15 de agosto de 2015 y sus normas anejas, en M. E. Olmos OrTega (ed.), Procesos de nulidad matrimonial tras la reforma del Papa Francisco, Madrid 2016, 17-62.

VILADRICH, J. P., Matrimonio y sistema matrimonial de la Iglesia. Reflexiones sobre la misión del derecho matrimonial canónico en la sociedad actual, Ius Canonicum 54 (1987) 495-534. 
